\title{
Peran Guru IPA dalam Pemanfaatan Media Pembelajaran Interaktif
}

\author{
${ }^{1}$ El Basthoh, ${ }^{2}$ Novyta \\ ${ }^{1}$ Prodi Pendidikan Fisika, STKIP YDB Lubuk Alung, Jln. Pulau Jantung, Kec. Lubuk Alung, \\ Kab. Padang Pariaman, SUMBAR, 25582 \\ ${ }^{2}$ Prodi Pendidikan Matematika, Sekolah Tinggi Keguruan dan Ilmu Pendidikan Media \\ Nusantara Citra, Jl. Raya Panjang, Komplek Green Garden Blok Z III, Jakarta 11520 \\ Email Korespondensi: el.basthoh@gmail.com
}

\begin{tabular}{|c|c|}
\hline Article Info & Abstract \\
\hline $\begin{array}{l}\text { Article History } \\
\text { Received: December } 2020 \\
\text { Revised: December } 2020 \\
\text { Published: December } 2020\end{array}$ & \multirow{2}{*}{$\begin{array}{l}\text { Inetractive learning media is a medium that can help students and teachers in } \\
\text { learning. This study aims to see the role of science teachers in the use of } \\
\text { instructional media. This type of research is qualitative non-experimental. The } \\
\text { population of this study were students of SMPN } 2 \text { Singai Aur Pasaman Barat. } \\
\text { Sampling using purposive sampling. Data were collected through a } \\
\text { questionnaire with } 2 \text { indicators. Based on data analysis using statistical data in } \\
\text { the form of percentages and relative frequencies, it was found that the } \\
\text { indicator of teacher control of the media used had a score of } 94.61 \% \text { and the } \\
\text { media indicators used were good, efficient, and could attract the attention of } \\
\text { students in the learning process } 88.31 \% \text { so that it could be concluded that the } \\
\text { role of science teachers in the use of interactive learning media has a score of } \\
91.46 \% \text { with a good category. }\end{array}$} \\
\hline $\begin{array}{l}\text { Keywords } \\
\text { Teacher Role; Learning } \\
\text { Media; Interactive Media }\end{array}$ & \\
\hline & \\
\hline $\begin{array}{l}\text { Sejarah Artikel } \\
\text { Diterima: Desember } 2020 \\
\text { Direvisi: Desember } 2020 \\
\text { Dipublikasi: Desember } 2020\end{array}$ & \multirow{2}{*}{$\begin{array}{l}\text { Media pembelajaran inetraktif merupakan media yang dapat membantu siswa } \\
\text { dan guru dalam pembelajaran. Penelitian ini bertujuan untuk melihat peran } \\
\text { guru IPA dalam pemanfaatan media pembelajaran. Jenis penelitian ini adalah } \\
\text { kualitatif noneksperimen. Populasi penelaitian ini adalah siswa SMPN } 2 \text { Singai } \\
\text { Aur Pasaman Barat. Pengambilan sampel menggunakan purposive sampling. } \\
\text { Pengambilan data dilakukan melalui angket dangan } 2 \text { indikator. Berdasarkan } \\
\text { analisis data menggunakan data statistik berupa persentase dan frekwensi } \\
\text { relative didapatkan bahwa indikator penguasaan guru terhadap media yang } \\
\text { digunakan memiliki skor } 94.61 \% \text { dan indikator media yang digunakan baik, } \\
\text { efisien, dan dapat menarik perhatian peserta didik dalam proses pembelajaran } \\
88.31 \% \text { sehingga dapat disimpulkan bahwa peran guru IPA dalam pemanfaatan } \\
\text { media pembelajaran interaktif memiliki skor sebesar } 91.46 \% \text { dengan kategori } \\
\text { baik. }\end{array}$} \\
\hline $\begin{array}{l}\text { Kata kunci } \\
\text { Peran Guru; Medi } \\
\text { Pembelajaran; } \\
\text { Media Interaktif }\end{array}$ & \\
\hline
\end{tabular}

Sitasi: Basthoh, E., Novyta, N. (2020). Peran Guru IPA dalam Pemanfaatan Media Pembelajaran Interaktif. Kappa Journal. 4(2), 158-164

\section{PENDAHULUAN}

Pada era Revolusi Industri 4.0 mau tidak mau guru harus memiliki kompetensi yang kuat, memiliki softskill critical thinking, kreatif, komunikatif, dan kolaboratif, dimana guru harus mampu memanfaatkan kemajuan teknologi informasi secara bijak serta sebagai inspirator bagi peserta didik yang dapat diwujudkan jika guru tidak berhenti belajar dan mengembangkan diri (Susanti, 2019). Pada kurikulum 2013 peran guru berkurang dibandingkan peran guru pada KBK dan KTSP yaitu sebagai pelaksana teknis sehingga membuka peluang bagi guru untuk dapat mengoptimalkan efektivitas pembelajaran di kelas dalam rangka meningkatkan kualitas pendidikan melalui peningkatan kompetensi guru serta optimalisasi guru dalam pembelajaran (Alawiyah, 2013). Dalam proses belajar-mengajar, guru memegang peran sebagai sutradara sekaligus aktor dan merupakan faktor yang sangat 
dominan dalam menentukan keberhasilan proses belajar-mengajar di kelas (Firmansyah, 2019).

Pada saat pembelajaran akan dilaksanakan, hendaknya seorang tenaga pendidik yang professional harus memahami karakteristik isi pesan pembelajaran yang akan disampaikan, agar tidak salah dalam memilih strategi pembelajarannya, interaksi pembelajaran, pengelolaan kelas, pemilihan bahan pembelajaran dan media pembelajaran, serta alat evaluasi yang akan digunakan (Hernawan et al., 2008). Pembelajaran akan lebih efektif jika menggunakan media pembelajaran yang bervariasi agar siswa tidak monoton dalam pembelajaran. Media sebagai komponen sistem pembelajaran memiliki fungsi yang dimuati pesan pembelajaran untuk disampaikan kepada siswa/mahasiswa (Rosdiana, 2018). Penggunaan media pembelajaran yang dikembangkan memberikan pengaruh pada peningkatan performa akademik peserta didik (Yektyastuti \& Ikhsan, 2016). Fungsi utama media pembelajaran adalah sebagai alat bantu mengajar yang turut mempengaruhi iklim, kondisi, dan lingkungan belajar yang ditata dan diciptakan oleh pendidik dimana pemakaian media pembelajaran dalam proses belajar mengajar dapat membangkitkan keinginan dan minat yang baru, membangkitkan motivasi dan rangsangan kegiatan belajar, dan bahkan membawa pengaruh-pengaruh psikologis terhadap siswa (Nurmadiah, 2016).

Melalui media pembelajaran dapat membuat proses belajar mengajar lebih efektif dan efesien serta terjalin hubungan baik antara guru dengan peserta didik. Selain itu, media dapat berperan untuk mengatasi kebosanan dalam belajar di kelas, jadi media pembelajaran adalah salah satu metode dalam mengatasi segala macam persoalan dalam mengajar, bukan saja mengatasi persoalan, namun media pembelajaran dapat memberi berbagai informasi yang komprehensif kepada peserata didik (Tafonao, 2018). Manfaat media dalam pembelajaran adalah: (1) Penyampaian materi pelajaran dapat diseragamkan. (2) Proses pembelajaran menjadi lebih jelas dan menarik. (3) Proses pembelajaran menjadi lebih interaktif. (4) Efisiensi waktu dan tenaga. (5) Meningkatkan kualitas hasil belajar siswa. (6) Media memungkinkan proses pembelajaran dapat dilakukan dimanapun dan kapanpun. (7) Media dapat menumbuhkan sikap positif siswa terhadap materi dan proses pembelajaran. (8) Mengubah peran guru ke arah yang lebih positif dan produktif (Karo-Karo \& Rohani, 2018).

Guru berperan besar dalam pengembangan media pembelajaran yang bervariatif, jika media pembelajaran yang digunakan belum bervariatif, guru harus melakukan inovasi terhadap media pembelajaran (Ichsan et al., 2018). Untuk mengembangkan media pembelajaran perlu diperhatikan prinsip VISUALS, yang dapat digambarkan sebagai singkatan dari kata-kata: Visible: mudah dilihat, Interesting: menarik, Simple: sederhana, Useful: isinya berguna/bermanfaat, Accurate: Benar (dapat dipertanggungjawabkan), Legitimate: masuk akal/sah, Structured: terstruktur/tersusun dengan baik (Nurseto, 2012). Salah satu media pembelajaran interaktif yang dapat digunakan oleh guru adalah media power point karena media power point merupakan aplikasi persentasi yang banyak digunakan untuk kepentingan proses pembelajaran. Media interaktif power point dapat digunakan sebagai alternatif dalam pembelajaran (Basthoh \& Novyta, 2018) karena terdapat pengaruh pemanfaatan media power point dalam pembelajaran terhadap prestasi belajar siswa (Wajdi, 2015) dimana prestasi belajar siswa yang diajarkan dengan media gambar elektronik lebih baik dibandingkan dengan media konvensional (Wajdi, 2017).

Berdasarkan latar belakang tersebut penelitian ini bertujuan untuk melihat peran guru IPA dalam pemanfaatan media interaktif yang dilihat dari 2 indikator melingkupi: 1) penguasaan guru terhadap media yang digunakan, dan 2) media yang digunakan baik, efisien, dan dapat menarik perhatian peserta didik dalam proses pembelajaran. 


\section{METODE}

Penelitian ini menggunakan metode kuantitatif non eksperimental yang bertujuan untuk memaparkan persepsi siswa terhadap peran guru dan media yang digunakan. Populasi dalam penelitian adalah 202 siswa dengan sampel penelitian 77 siswa. Teknik pengambilan sampel dilakukan dengan purposive sampling, yang ditarik dengan sengaja karena alasanalasan diketahuinya sifat sampel itu. Penelitian lapangan (Field Reaserch) untuk memperoleh data lapangan berupa angket. Indikator instrument pada penelitian ini dapat dilihat pada tabel 1 berikut ini:

Tabel 1. Indikator Instrumen Angket.

\begin{tabular}{ll}
\hline Indikator & Pertanyaan \\
\hline Penguasaan guru terhadap & Guru menguasai media yang digunakan \\
media yang digunakan & $\begin{array}{l}\text { Guru kreatif dalam membuat dan menyajikan media pembelajaran } \\
\text { Media yang digunakan bervariasi }\end{array}$ \\
& $\begin{array}{l}\text { Media yang digunakan oleh guru hanya satu macam } \\
\text { Guru sangat terampil dalam menggunakan media pada pelajaran IPA }\end{array}$ \\
$\begin{array}{ll}\text { Media yang digunakan } \\
\text { baik, efisien, dan dapat }\end{array}$ & $\begin{array}{l}\text { Media dapat membantu saya dalam kelengkapan /melengkapi sumber } \\
\text { benarik perhatian peserta }\end{array}$ \\
$\begin{array}{l}\text { Media dapat menggambarkan sesuatu yang abstrak } \\
\text { didik dalam proses } \\
\text { pembelajaran }\end{array}$ & $\begin{array}{l}\text { Belajar menggunakan media hanya membuang-buang waktu } \\
\text { Dengan memanfaatkan media, pembelajaran IPA lebih hemat waktu }\end{array}$ \\
\hline
\end{tabular}

Pengelolaan data pada penelitian ini menggunakan editing, koding, skoring, tabulasi dan analisis data untuk dapat membantu dalam mengambil kesimpulan penelitian. Respon yang diberikan pada angket memiliki nilai 4 tertinggi dan 1 terendah. Analisis data menggunakan rumusan:

Keterangan:

$$
P=\frac{f}{N} x 100 \%
$$

$\mathrm{P}=$ Persentase

$f=$ Frekwensi

$\mathrm{N}=$ Number of cases

Untuk memberikan interpretasi dan persentase hasil angket yang diperoleh digunakan pedoman interpretasi pada tabel 2 berikut:

Tabel 2. Penetapan Interpretasi berdasarkan persentase interval

\begin{tabular}{ll}
\hline Interval (\%) & Kategori \\
\hline $76-100$ & Baik \\
$56-75$ & Cukup Baik \\
$41-55$ & Kurang Baik \\
$0-40$ & Tidak Baik \\
\hline
\end{tabular}

\section{HASIL DAN PEMBAHASAN}

Hasil dan pembahasan dapat dilihat dari 2 indikator dengan 9 item pertanyaan yang merupakan respon siswa dan dirangkum pada gambar 1 serta gambar 2 berikut: 


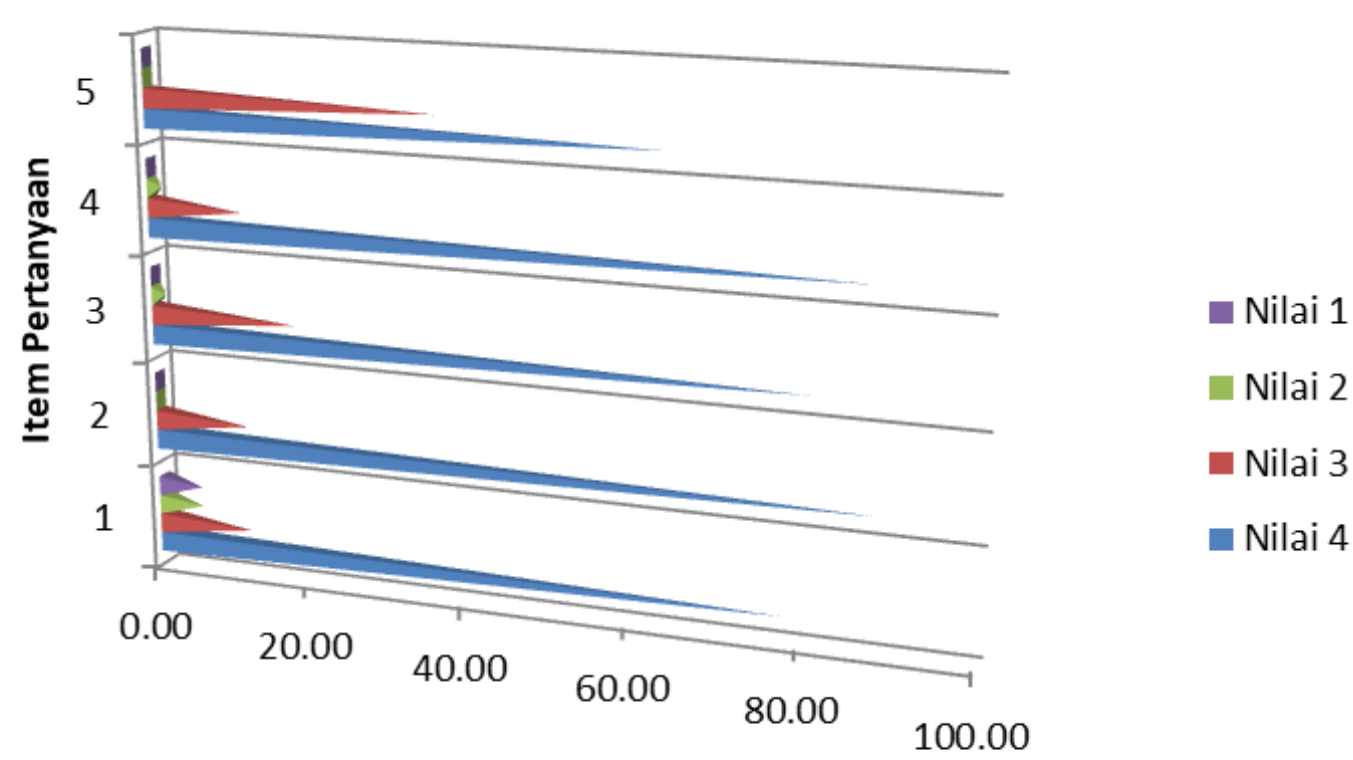

\% Frekwensi Nilai

Gambar 1. Grafik respon siswa mengenai penguasaan guru terhadap media yang digunakan.

Berdasarkan Gambar 1 dapat diketahui bahwa dari 5 pertanyaan yang diberikan pada indikator pertama nilai 4 mendominasi dari semua item yang ada. Pertanyaan item ke 1 "guru menguasai media yang digunakan" memiliki nilai yang beragam. Pada respon siswa masih ada penilaian yang menyampaikan bahwa guru belum menguasai media yang digunakan, namun $77,92 \%$ siswa menyatakan guru menguasai media yang digunakan. Selama proses pembelajaran, selain memiliki kemampuan dalam menjelaskan materi ajar, guru juga harus menguasai bagaimana menggunakan media yang dibuat, agar tujuan dari pembuatan media tidak melenceng dan membuat materi menjadi kabur, sehingga tujuan pembelajaran dapat tercapai. Oleh karena itu, sebelum media itu digunakan, guru harus memastikan bahwa media yang akan digunakan dalam pembelajaran dapat digunakan dengan baik, sehingga proses pembelajaran dapat berjalan dengan lancar. Seiring dengan hal tersebut dibuktikan bahwa penguasaan dan keterampilan guru dalam penggunaan media merupakan hal yang penting dalam proses pembelajaran.

Nilai 4 terbanyak dimiliki oleh pertanyaan item ke 2 sebesar $88,31 \%$ dalam hal ini siswa menyampaikan bahwa guru telah kreatif dalam pembuatan dan menyajikan media pembelajaran yang membuat siswa tertarik dan bersemangat dalam belajar, karena media yang diberikan dilengkapi dengan animasi, audia dan video yang membuat siswa dapat memahami pembelajaran dengan lebih mudah. Selama ini guru hanya menjelaskan materi, jarang sekali menggunakan media dalam menyampaikan pembelajaran. Media yang diberikan harus lah bervariasi bukan hanya satu media saja agar siswa dapat menimbulkan semangat belajar siswa. sejalan dengan hal tersebut diwakili oleh pertanyaan item ke 3 dan ke 4 dimana respon siswa telah menunjukkan bahwa media yang digunakan sudah bervariasi. Dimana pada item pertanyaan no 3 "Media yang digunakan bervariasi" mendapatkan penilaian 4 sebanyak $80,52 \%$ dan pada item pertanyaan no 4 "media yang digunakan oleh guru hanya satu macam" mendapatkan nilai 4 sebanyak $87,01 \%$. Pertanyaan item ke 5 "guru sangat terampil dalam menggunakan media pada pelajaran IPA" memiliki nilai 4 yang paling sedikit dibanding item pertanyaan yang lainnya, namun penilaian peritemnya penilaian 4 masih merupakan nilai terbesar yaitu sebesar $63,64 \%$ yang merupakan bukti bahwa guru haruslah terampil dalam penggunaan media dalam pembelajaran yang diberikan namun. 


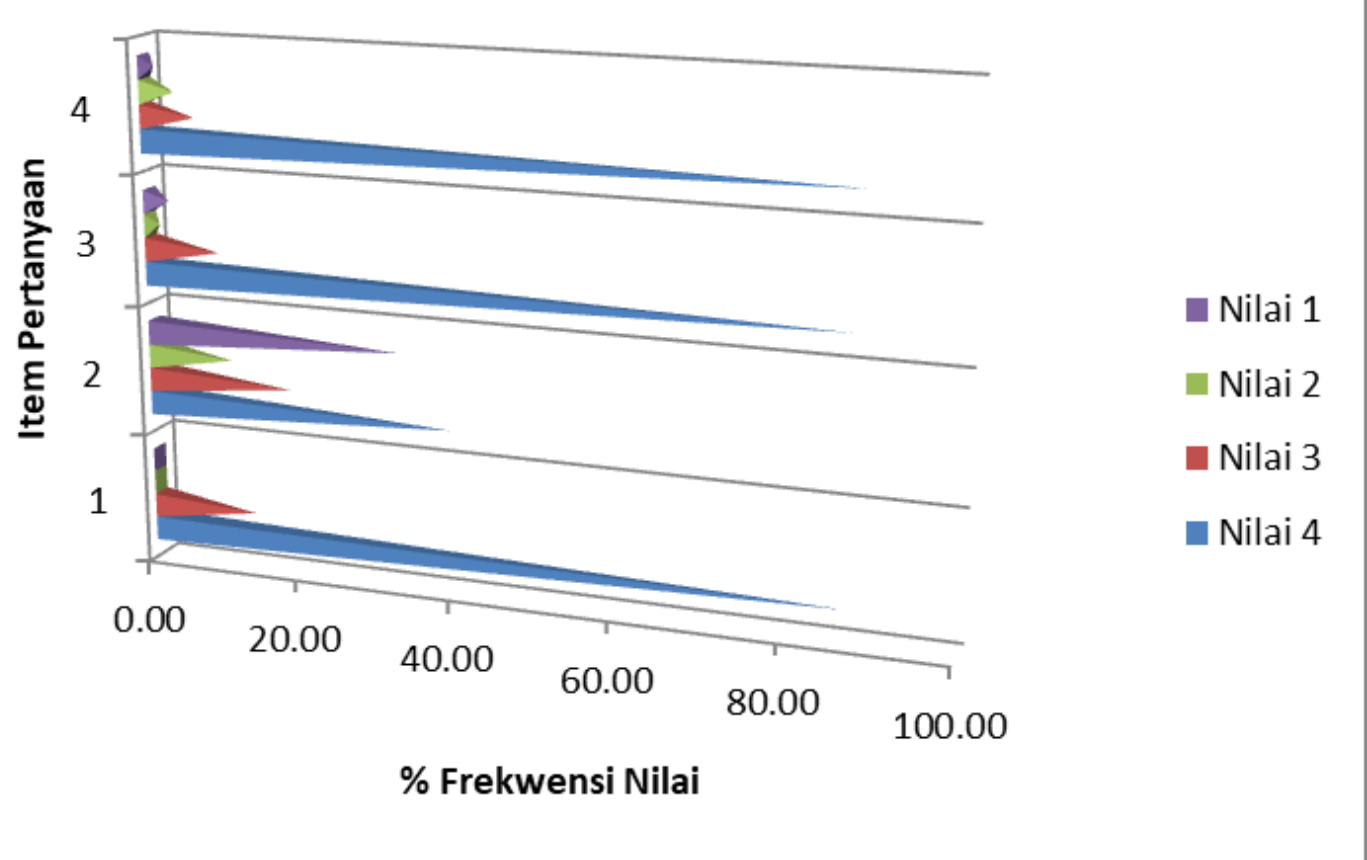

Gambar 2. Grafik media yang digunakan baik, efisien, dan dapat menarik perhatian peserta didik dalam proses pembelajaran

Berdasarkan Gambar 2 dapat diketahui pada indikator ke 2 item pertanyaan ke 1 "media dapat membantu saya dalam kelengkapan /melengkapi sumber belajar" mendapatkan respon yang baik dari siswa dimana $87,01 \%$ respon berada pada nilai 4 . Pada item pertanyaan no 2 " media dapat menggambarkan sesuatu yang abstrak" memiliki nilai 4 sebesar 38,96\% sehingga media yang digunakan guru masih dirasa perlu dikembangkan agar media dapat membantu dalam pencapaian pembelajaran termasuk menggambarkan materi yang selama ini abstrak.

Item pertanyaan ke 3 dan ke 4 mewakili penggunaan waktu belajar dengan menggunakan media diamana "dengan memanfaatkan media, pembelajaran IPA lebih hemat waktu". Item pertanyaan ini memiliki nilai 4 terbanyak, karena media yang digunakan adalah media interaktif, sehingga secara individu siswa terlibat langsung dalam pembelajaran, jika kurang memahami tentang materi dapat bertanya langsung kepada guru. Karena pekerjaan guru menjadi lebih ringan dengan bantuan media, maka waktu yang digunakan dapat lebih efisien. Guru atau siswa tidak perlu mencatat materi yang dipelajari, hanya cukup meng-klik saja maka pembelajaran dapat berjalan dengan lancar.

Berdasarkan skor yang ada pada kategori penilaiaan yang telah ditetapkan maka dapat di dilihat Interpretasi pada Tabel 3 berikut berikut:

Tabel 3. Interpretasi Peran Guru IPA dalam Pemanfaatan Media Pembelajaran Interaktif

\begin{tabular}{lll}
\hline Indikator & Respon $(\%)$ & Kategori \\
\hline $\begin{array}{l}\text { Penguasaan guru terhadap media yang } \\
\text { digunakan }\end{array}$ & 94.61 & baik \\
$\begin{array}{l}\text { Media yang digunakan baik, efisien, } \\
\text { dan dapat menarik perhatian peserta } \\
\text { didik dalam proses pembelajaran }\end{array}$ & 88.31 & baik \\
\hline Rata-rata respon & 91.46 & Baik \\
\hline
\end{tabular}


Berdasarkan tabel 3 dapat diketahui bahwa kedua indikator memiliki kategori baik. penguasaan guru terhadap media dan juga pemilihan dan penggunaan media yang digunakan merupakan hal penting dalam pembelajaran sehingga siswa dapat terbantu dengan baik. Guru sangat berperan penting dalam memanfaatkan media. Media yang digunakan haruslah menggambarkan situasi dari materi yang dipelajari. Media sebagai jembatan penghubung antara penjelasan guru dan pemahaman siswa.

\section{KESIMPULAN}

Berdasarkan tujuan yang telah disampaikan sebelumnya, hasil dan pembahasan yang dijabarkan sebelumnya penelitian ini didapatkan bahwa indikator penguasaan guru terhadap media yang digunakan memiliki skor $94.61 \%$ dengan kategori baik. Indikator media yang digunakan baik, efisien, dan dapat menarik perhatian peserta didik dalam proses pembelajaran $88.31 \%$ dengan kategori baik. Jadi dapat disimpulkan bahwa peran guru IPA dalam pemanfaatan media pembelajaran interaktif memiliki skor sebesar $91.46 \%$ dengan kategori baik.

\section{SARAN}

Berdasarkan tujuan, hasil dan pembahasan yang telah diutarakan dapat disimpulkan bahwa peran guru dalam pembuatan media dan penggunaanya merupakan point penting dalam pencapaian pembelajaran bagi siswa dimana respon yang didapatkan sebesar $91,46 \%$ dengan kategori baik.

\section{UCAPAN TERIMA KASIH}

Terimakasih kepada Direktorat Riset dan Pengabdian Masyarakat. Direktorat Jendral Penguatan Riset dan Pengembangan Kementrian Riset, Teknologi, dan Pendidikan Tinggi.

\section{DAFTAR PUSTAKA}

Alawiyah, F. (2013). Peran Guru dalam Kurikulum 2013. Aspirasi.

Basthoh, E., \& Novyta, N. (2018). Media Interaktif Power Point sebagai Alternatif dalam Pembelajaran IPA. Psychopolytan: Jurnal Psikologi, 1(2), 132-139. http://jurnal.univrab.ac.id/index.php/psi/article/view/535/365

Firmansyah, J. (2019). Kompetensi dan profesionalisme guru ipa. Jurnal Visi Ilmu Pendiidkan.

Hernawan, A. H., Permasih, \& Dewi, L. (2008). Panduan Pengembangan Bahan Ajar. In Depdiknas Jakarta.

Ichsan, I. Z., Dewi, A. K., Hermawati, F. M., \& Iriani, E. (2018). Pembelajaran IPA dan Lingkungan: Analisis Kebutuhan Media Pembelajaran pada SD, SMP, SMA di Tambun Selatan, Bekasi. JIPVA (Jurnal Pendidikan IPA Veteran). https://doi.org/10.31331/jipva.v2i2.682

Karo-Karo, I. R., \& Rohani, R. (2018). Manfaat Media dalam Pembelajaran. AXIOM : Jurnal Pendidikan Dan Matematika. https://doi.org/10.30821/axiom.v7i1.1778

Nurmadiah, N. (2016). MEDIA PENDIDIKAN. Al-Afkar: Jurnal Keislaman \& Peradaban. https://doi.org/10.28944/afkar.v5i1.109

Nurseto, T. (2012). Membuat Media Pembelajaran yang Menarik. Jurnal Ekonomi Dan Pendidikan. https://doi.org/10.21831/jep.v8i1.706

Rosdiana, R. (2018). Pengembangan Media Pembelajaran Berbasis Komputer. Al-Khwarizmi: Jurnal Pendidikan Matematika Dan Ilmu Pengetahuan Alam. https://doi.org/10.24256/jpmipa.v1i2.95

Susanti, E. R. M. yanti S. M. (2019). Peran Guru Fisika Di Era Revolusi Industri 4.0. Difraction.

Tafonao, T. (2018). Peranan Media Pembelajaran dalam Meningkatkan Minat Belajar 
Mahasiswa. Jurnal Komunikasi Pendidikan. https://doi.org/10.32585/jkp.v2i2.113

Wajdi, B. (2015). Pemanfaatan Media Power Point dalam Pembelajaran Fisika dengan Pendekatan Konstruktivisme. Jurnal Pendidikan Fisika. https://doi.org/10.24127/jpf.v3i2.234

Wajdi, B. (2017). Pengaruh Media Gambar Elektronik Ditinjau dari Motivasi Belajar Terhadap Prestasi Belajar Siswa. Kappa Journal, 1(2), 25-31. http://ejournal.hamzanwadi.ac.id/index.php/kpj/article/view/Wajdi/pdf_13

Yektyastuti, R., \& Ikhsan, J. (2016). Pengembangan media pembelajaran berbasis android pada materi kelarutan untuk meningkatkan performa akademik siswa SMA. Jurnal Inovasi Pendidikan IPA. https://doi.org/10.21831/jipi.v2i1.10289 